\title{
PENGEMBANGAN APLIKASI SIMULASI PERDAGANGAN SAHAM DENGAN SECTOR ROTATION DAN LINEAR PROGRAMMING
}

\author{
Tomy G. Soemapradja ${ }^{1}$; Jerry Marcellinus Logahan²; Hengky Ongowarsito ${ }^{3}$ \\ ${ }^{1,2}$ Management Department, School of Business Management, BINUS University \\ ${ }^{3}$ School of Information System, BINUS University \\ Jln. K.H. Syahdan No. 9, Palmerah, Jakarta Barat 11480 \\ gurtama@yahoo.com; jerrymarcellinus@yahoo.com; henkie@binus.edu
}

\begin{abstract}
In strategic development a university will shift from teaching university to research university. It is because academic outcomes will be more useful if they can be commercialized by industries, which help improve the ranking of a university. The development of capital market and management measures of Indonesia Stock Exchange during the last 8 years aiming at academicians in order to identify and be interested in investing in the stock market needs to be observed. That is by providing a simulation so that more students can improve the competition at their graduation. The involvement of industry selection strategy and portfolio management will be required so that the expertise and ability to manage investments in the capital market can be better. So, it necessarily requires a development of simulation application of stock trading with business rotation and linear programming.
\end{abstract}

Keywords: stock market, industry selection strategy, business rotation, linear programming

\begin{abstract}
ABSTRAK
Dalam perkembangan strategis, sebuah universitas akan beralih dari teaching university menjadi research university, karena hasil akademis akan lebih bermanfaat jika dapat dikomersialisasi dengan pihak industri, yang turut meningkatkan peringkat sebuah universitas. Perkembangan pasar modal dan langkah manajemen Bursa Efek Indonesia selama 8 tahun terakhir yang membidik kalangan akademis agar mengenal dan tertarik berinvestasi di pasar modal perlu dicermati, yaitu dengan memberikan sebuah simulasi agar para mahasiswa lebih dapat meningkatkan kompetisi mereka saat kelulusan nanti. Keterlibatan strategi pemilihan industri dan manajemen portofolio akan diperlukan agar keahlian dan kemampuan mengelola investasi di pasar modal dapat lebih baik, sehingga diperlukan pengembangan aplikasi simulasi perdagangan saham dengan business rotation dan linear programming.
\end{abstract}

Kata kunci: pasar modal, strategi pemilihan industri, rotasi bisnis, program linear 


\section{PENDAHULUAN}

Perkembangan strategis sebuah universitas, selain mengutamakan layanan dan fasilitas untuk mendukung proses belajar-mengajar, juga membuat akses ke industri agar peluang kerja para lulusannya lebih tinggi daripada universitas lainnya. Fasilitas yang layak, bahkan mewah, dengan mudah dapat ditiru oleh universitas lain untuk memenangkan persaingan di industri pendidikan. Akan tetapi, budaya sebuah universitas tidak mudah diduplikasi oleh universitas pesaingnya dalam waktu dekat karena dibutuhkan 10-15 tahun untuk dapat menyamainya. Belum lagi, hasil riset universitas yang diakui baik nasional maupun internasional akan menjadi natural barrier bagi universitas pesaing karena hal tersebut akan relevan dengan peringkat universitas di mata dunia. Sayangnya, riset yang dihasilkan universitas lebih banyak berhenti di perpustakaan ataupun di jurnal, alias belum diberdayakan untuk dimanfaatkan oleh dunia industri, atau bahkan di kalangan internal universitas tersebut. Kecenderungan saat ini universitas berlomba-lomba "menjual” hasil riset agar dapat diterima oleh industri yang dapat dikomersialisasikan, sehingga perkembangan strategis sebuah universitas bergerak dari teaching university menjadi research university. Pembukaan akses ke dunia industri melalui kerja sama atau penggunaan hasil riset tentu menjadi sebuah prestasi yang membanggakan serta bernilai jual-yang menjadi target ideal terbaik.

Penelitian ini berusaha memosisikan hasil risetnya agar dapat diterima (lebih jauh) ke kalangan umum, bahkan berpotensi ke industri yang lebih spesifik, yaitu pasar modal. Pada saat sebuah perekonomian sudah membaik, maka para pemiliki modal ataupun calon investor, mulai mencari wadah investasi yang lebih menarik daripada sekadar menempatkan dananya di sektor perbankan. Sehingga dalam perkembangannya, manajemen Bursa Efek Indonesia (BEI) pun sejak 8 tahun terakhir lebih agresif melakukan kerja sama dalam bentuk Pusat Pembelajaran ataupun Data Perdagangan saham yang dibuka di universitas. Bahkan mereka bekerja sama dengan pihak ketiga, yaitu broker, sehingga kalangan akademis pun selain dapat melakukan riset, juga dapat bertransaksi di bursa efek melalui broker. Langkah manajemen BEI merupakan upaya untuk mendidik pasar agar "pasar" lebih mengerti, tertarik, dan memanfaatkan lahan investasi dalam bentuk obligasi, saham ataupun instrumen derivatif di pasar modal. Hal ini bertujuan positif namun memang diperlukan sebuah wawasan minimum khusus yang perlu dipahami oleh para calon investor di pasar modal, khususnya mahasiswa, untuk kalangan akademik. Ibarat seorang calon pilot pesawat tempur, saat awal mereka dididik dalam akademi militer pun tidak langsung dipinjami pesawat tempur dan langsung terbang, tentu tidak demikian. Para calon pilot harus mengikuti latihan dalam bentuk flight simulator dengan misi atau skenario-skenario khusus yang diberikan oleh para instrukturnya. Dalam hal ini, para calon investor pun perlu dididik dalam sebuah simulasi perdagangan saham dengan skenario tertentu yang dihubungkan dengan materi dan tujuan akhir pembelajaran.

Simulasi perdagangan saham akan lebih terasa manfaatnya jika menggunakan data-data yang bervariasi, misal 5-10 tahun terakhir, untuk diangkat dalam beberapa skenario yang menarik, misalkan dalam kondisi ekonomi booming, normal dan ressesion, atau kombinasi dari ketiganya. Sejalan dengan itu, para mahasiswa di jurusan manajemen pun perlu diberikan simulasi yang relevan dengan strategi investasi -bahkan lebih spesifik- ke strategi keuangan dan investasi yang relevan dengan pasar modal untuk meningkatkan kompetisi mereka. Hasil akhir simulasi tentu akan dipengaruhi oleh fluktuasi kondisi ekonomi dan bursa saham, yang juga dipengaruhi oleh pilihan industri yang berisiko lebih rendah namun berkinerja lebih baik daripada industri lainnya. Strategi utama dalam upaya mengurangi risiko, adalah melakukan investasi pada industri (sector) yang sedang berada pada siklus yang menguntungkan, serta berpindah ke industri lainnya saat industri sebelumnya berkinerja kurang baik, dengan kata lain melakukan business rotation. Pada kenyataanya, investasi akan lebih baik jika “don't put all your eggs in one basket”, alias memungkinkan keputusan pengguna simulasi melakukan alokasi pada dua atau lebih industri yang berbeda. Dengan demikian hal ini akan berdampak pada keputusan alokasi dana (persentase komponen saham) yang akan berpengaruh pada kinerja portofolio 
secara keseluruhan. Perhitungan optimalisasi membutuhkan langkah yang cukup kompleks dan berpotensi terjadi kesalahan hitung jika dilakukan secara manual. Oleh karenanya penelitian dapat menggunakan program yang familiar di kalangan akademis, memiliki fungsi khusus yang dapat dimanfaatkan untuk optimalisasi portofolio yang dilakukan secara simultan dengan skenario-skenario tertentu.

Ruang Lingkup penelitian adalah sebagai berikut. Pertama, data simulasi menggunakan data 10 tahun terakhir (harian). Dengan asumsi 1 tahun bursa diperkirakan 240 hari kerja bursa, maka diperkirakan akan terdapat 2.400-an data harian. Saat ke-2.400 data tersebut dihubungkan dengan indeks bursa, indeks sektor, indeks LQ45, 45 saham dalam LQ45, maka diperkirakan akan total terdapat 120.000-an data yang perlu dikelola dengan sebuah database yang stabil. Kedua, poin pertama menyebabkan saat pengembangan simulasi menggunakan sebuah program datasheet yang dimodifikasi dengan program VBA/Macro yang menjadi sebuah database. Mengingat MsExcel 2003 lebih stabil dan memiliki fungsi yang lebih lengkap daripada MsExcel 2007, maka aplikasi simulasi akan dibangun dari MsExcel 2003. Fungsi khusus yang akan digunakan dalam simulasi perdagangan adalah Solver, yaitu sebuah program tambahan (add-ins) dalam MsExcel yang perlu diaktivasi sebelum menjalankan simulasi. Ketiga, bidang ilmu dan analisi kuantatif yang terlibat dalam penelitian ini meliputi bidang statistik bisnis, ilmu ekonomi makro dan ekonomi mikro, keuangan, khususnya pasar modal.

Identifikasi masalah dalam penelitian ini, yaitu pertama, bagaimanakah siklus Bursa Efek Indonesia selama 10 tahun terakhir. Kedua, fitur dan skenario apa saja yang perlu dilibatkan dalam simulasi perdagangan saham untuk meningkatkan Analytical Skill berdasarkan siklus Bursa Efek Indonesia. Sementara tujuan dan manfaat penelitian ini adalah pertama, untuk menganalisis dan merancang model siklus bursa efek dan menyusun skenario simulasi berdasarkan data 10 tahun terakhir. Kedua, untuk merancang aplikasi simulasi perdagangan yang dilengkapi dengan analisis sector rotation dan optimalisasi portofolio saham dengan Linear Programming, berdasarkan rancangan model siklus bursa efek dan skenario dari tujuan pertama.

\section{Studi Pustaka}

Tujuan investasi adalah untuk menghasilkan arus kas masuk yang lebih besar daripada arus kas yang keluar (Fabozzi, 2007). Investasi berdasarkan jenis instrumennya dapat dibedakan menjadi pasar uang (money market) dan pasar modal (capital market), seperti yang dikemukakan oleh Elton dan Gruber (2011). Saat investor ingin mengharapkan laba yang lebih tinggi dan bersedia mengambil risiko lebih besar, maka disarankan menggunakan instrumen keuangan yang disediakan di pasar modal, yaitu obligasi, saham dan instrumen derivatif, dengan kata lain : more return, more risk. Guna mengoptimalkan hasil investasi, diperlukan analisis pasar sebelum memutuskan untuk membeli atau menjual sebuah aset. Analisis pasar meliputi analisis fundamental dan teknikal. Analisis fundamental meliputi analisis kondisi ekonomi makro dan ekonomi mikro, sampai dengan siklus bursa - bahkan sampai siklus industrinya (Kettell, 2002). Dengan demikian analisis siklus sektor (industri) akan sangat membantu para investor untuk membuat keputusan investasi, sehingga investor dapat mengalokasikan dananya pada sektor yang berisiko rendah serta menguntungkan; dan selanjutnya saat siklus industri tersebut sudah tidak menguntungkan, maka investor dapat pindah ke industri lain berdasarkan rekomendasi yang terbaik. Langkah atau strategi ini dikenal dengan sector rotation (Owen \& Griffith, 2006). Dalam praktiknya, walaupun investor telah memiliki pedoman untuk membuat keputusan berinvestasi pada sebuah sektor industri, tetap saja perlu melakukan diversifikasi risiko dengan mengalokasikan dana pada beberapa aset yang berada pada industri yang berbeda, alias melakukan manajemen portofolio (Elton \& Gruber, 2011). Manajemen portofolio bertujuan untuk mengurangi risiko sistematik sehingga kinerja portofolio semakin baik (diversifikasi risiko). 
Kinerja saham dapat diukur dari Sharpe Ratio, Kataoka Ratio, Jensen Ratio, Coefficient Variation, dan lainnya (Elton \& Gruber, 2011). Khusus untuk Coefficient Variation (CV), indikator ini langsung membandingkan antara tingkat risiko dan rata-rata tingkat laba sebuah portofolio. Sehingga solusi optimum akan mengarah ke dua alternatif, yaitu: minimalisasi risiko atau maksimalisasi laba. Hanya saja faktor risiko dan laba harus selalu paralel terlibat; dengan kata lain "High Risk - High Return" atau "Low Risk - Low Return”, maka alternatif solusi menjadi Alternatif Minimalisasi risiko: Penurunan risiko lebih besar dari penurunan laba dan Alternatif Maksimalisasi laba: Kenaikan laba lebih besar dari kenaikan risiko. Saat investor menggunakan tingkat laba sebagai kriteria pemilihan aset, maka investor cenderung memilih aset yang memiliki tingkat laba tertinggi, sebaliknya menggunakan tingkat risiko sebagai pertimbangan berinvestasi, maka investor cenderung memilih aset yang memiliki risiko yang terendah. Saat terdapat beberapa aset yang memiliki tingkat laba dan tingkat risiko berbeda, maka investor perlu indikator lain, yang intinya, memaksimalisasi tingkat laba sekaligus meminimalisasi tingkat risiko, seperti yang dijelaskan dalam teori pemilihan aset Markovic (Elton \& Gruber, 2011). Untuk dapat menentukan indikator tersebut, dibutuhkan perhitungan yang cukup kompleks, terlebih lagi melibatkan lebih dari 5 aset. Salah satu metode kuantitatif yang dapat dihubungkan dengan kombinasi tujuan maksimalisasi (return) sekaligus minimalisasi (risk), alias menjadi tujuan optimalisasi, adalah Linear Programming (LP). LP adalah metode kuantitatif yang menggunakan persamaan matematis dengan dua fungsi yang berbeda, yaitu fungsi tujuan (objective) dan fungsi batasan (contraints). Model LP akan mencari solusi dari variabel-variabel yang dianalisis yang memenuhi kriteria fungsi batasan (Anderson dkk., 2011), sehingga model LP dapat dimanfaatkan untuk menentukan daerah solusi yang dapat mengoptimalkan kinerja portofolio saham dari beberapa sektor atau industri yang berbeda. Simulasi yang bertujuan untuk membandingkan hasil data historis dengan mengulang kembali simulasi menggunakan model tertentu dikenal dengan back-testing simulation (Bank, 1998). Pengguna simulasi di-update setiap beberapa waktu, tentu membutuhkan waktu saat menyelesaikan sebuah perhitungan yang mendukung keputusan, terlebih lagi jika perlu menyelesaikan perhitungan yang kompleks-yang berhubungan dengan optimalisasi portofolio. Sehingga simulasi tersebut membutuhkan modul fungsi tambahan yang dapat menjalankan fungsi optimalisasi portofolio. Saat simulasi menggunakan file berbasis MsExcel, maka fungsi Solver dapat dimanfaatkan untuk menyelesaikan optimalisasi portofolio dalam waktu yang singkat-sebagai data kuantitatif penguat rekomendasi keputusan saat simulasi. Dalam hal ini dapat diselesaikan dengan financial modeling dengan Ms Excel (Barlow, 2005).

\section{METODE}

Jenis data penelitian ini adalah data sekunder yang bersumber dari studi pustaka, baik yang bersifat media cetak maupun media Internet yang terpercaya, misalnya dari situs Bank Indonesia, kantor berita Reuters, Bapepam LK, Finance Yahoo.com, dan lainnya. Sebagaimana layaknya sebuah simulasi, penelitian ini berusaha melibatkan data-data yang terbaru, sehingga akan menggunakan datadata kuantitatif yang dapat diakses sebagai data publik dalam periode 10 tahun terakhir, yaitu dari 2001-2011, sehingga metode pengumpulan sampel termasuk dalam Purposive Sampling. Pengumpulan sampel menggunakan kriteria tertentu, yaitu waktu terkini (updated). Metode yang akan terlibat dalam analisis dan perhitungan data, meliputi beberapa metode statistik terapan, yaitu: descriptive statistics untuk menjelaskan deskripsi sampel, distribusi data sampel; cyclical forecasting untuk menentukan model peramalan data yang bersifat berfluktuatif secara musiman atau siklus; statistic control untuk menentukan batas-batas siklus ekonomi dan bursa, Excess Return to Beta Ratio (ERB) untuk menentukan kinerja portofolio optimum dan Linear programming untuk mengoptimalisasikan kinerja portofolio yang dikombinasikan dengan ERB.

Dasar software simulasi menggunakan format file Ms Excel - Macro Enabled (*.xls untuk versi Ms Excel 2003 atau *.xlsm untuk versi Ms Excel 2007 ke atas). Metode perancangan simulasi 
dengan Spreadsheet Decision Modeling (Guerrero, 2010) yang dipadukan dengan fungsi statistik dan program Macro/VBA. Baik data mentah maupun hasil penelitian akan disajikan dalam bentuk tabel, grafik (linechart, candlestick chart), ataupun bagan khusus. Saat dihubungkan dengan tampilan layar aplikasi simulasi dikelompokkan dalam 6 tahap: (1) pengumpulan data yang direkam dalam database; (2) analisis dan perancangan persamaan matematis; (3) menentukan skenario simulasi, menentukan prosedur simulasi sampai dengan optimalisasi portofolio; (4) perancangan aplikasi simulasi; (5) uji coba simulasi perdagangan, dilakukan pada kesempatan khusus dengan mengundang dosen dan mahasiswa yang berminat untuk mendalami tentang pasar modal, meminta saran dan kritik konstruktif untuk menyempurnakan rancangan simulasi; dan (6) diseminasi dan publikasi ke jurnal nasional atau internasional.

\section{HASIL DAN PEMBAHASAN}

\section{Pengembangan Simulasi}

\section{Risiko Investasi dan Risiko Bisnis}

Salah satu risiko yang perlu dipertimbangkan dalam investasi adalah risiko bisnis (business risk). Risiko bisnis erat kaitanya dengan siklus bisnis (business risk). Para peneliti dan banyak sumber referensi menyatakan bahwa sumber risiko adalah ketidakpastian (uncertainty), karena ketidakpastian akan menyebabkan ketidakstabilan (fluctuation atau volatitiy). Makin fluktuatif berarti makin riskan, dengan demikian risiko bisnis akan berkorelasi langsung dengan fluktuasi bisnis. Sehingga faktor penentuan waktu (timing) berinvestasi pada sebuah atau beberapa industri pun menjadi pertimbangan utama agar menghasilkan investasi yang sehat dan berkelanjutan (Fabozzi \& Choudhry, 2004), tidak hanya pertimbangan historis-asumtif yang menghasilkan Return on Investment (ROI) menguntungkan.

Untuk dapat menentukan "kapan” (waktu) dan "di mana” (industri) dan "berapa” (alokasi dana investasi), konsep investasi perlu dilengkapi konsep manajemen yang cukup kompleks, yang perlu dijawab satu demi satu, dengan analogi seperti obat khusus dalam terapi pasien-obat yang satu harus mendukung obat lainnya. Sebab jika obat yang satu berkontradiksi dengan obat lainnya, hasilnya justru merugikan pasien (investor). Penelitian akan menggunakan metode: (a) waktu yang tepat untuk berinvestasi pada sebuah sektor industri, akan merujuk pada siklus ekonomi (Reilly \& Brown, 2009); (b) tempat (manakah) industri yang tepat untuk berinvestasi saat itu; berdasarkan poin a, akan merujuk pada siklus industri yang sudah dikelompokkan menjadi beberapa sektor industri; (c) jumlah alokasi dana yang menghasilkan portofolio optimum, akan merujuk pada kombinasi metode Linear Programming dan manajemen portofolio.

\section{Siklus Industri dan Siklus Ekonomi}

Terdapat beberapa sumber referensi pendukung tentang pengelompokkan sektor industri. Reilly dan Brown (2009) menghubungkan siklus ekonomi dan sektor industri pengelompokan sektor industri pada referensi di atas belum terlalu detail, serta belum menghubungkan dengan siklus bursa (sebagai parameter investasi di pasar modal). Murphy (2011) menggambarkan hubungan yang lebih "lengkap", antara sektor industri, siklus ekonomi dan siklus bisnis/industri. Meskipun Owen (2008) dan Murphy (2012) sudah menghubungkan sektor industri, siklus ekonomi, dan siklus bursa, visualisasi siklus ekonomi belum terlihat secara tegas. Oleh karenanya, penelitian merujuk sebuah situs khusus yaitu www.streettalklive.com. Untuk selanjutnya, pengembangan simulasi akan menggunakan pedoman seperti yang dilakukan oleh situs tersebut. Berikut ini adalah keterangan dari setiap istilah yang digunakan dalam pengembangan simulasi: pertama, kondisi bursa saham: bear market (kinerja bursa mengalami penurunan yang signifikan), market bottom (kinerja bursa berada 
pada titik terendah), bull market (kinerja bursa mengalami kenaikan yang signifikan), market top (kinerja bursa berada pada titik tertinggi); kedua, kondisi ekonomi: early recession (tahap awal kelesuan ekonomi), full recession (tahap kelesuan ekonomi yang berkepanjangan), early recovery (tahap awal pemulihan ekonomi), full recovery (tahap tertinggi pemulihan ekonomi).

Sebelum melakukan pemetaan setiap sektor industri dalam siklus industri dan siklus ekonomi, penelitian ini akan mengacu pada pembagian sektor berdasarkan yang terjadi pada bursa saham Indonesia, yaitu Bursa Efek Indonesia (BEI). BEI memiliki 9 pembagian industri (www.idx.co.id), yaitu: Pertanian (Agriculture), Industri Dasar dan Kimia (Basic Industry), Barang Konsumsi (Consumer Goods), Keuangan (Finance), Infrastruktur, Utilitas dan Transportasi (Infrastructures), Manufaktur (Manufactures), Pertambangan (Minning), Aneka Industri (Miscellaneous), Properti dan Real Estate (Properties), Perdagangan, Jasa dan Investasi (Trade)

\section{Adaptasi Matematika dalam Siklus}

Berdasarkan Reilly \& Brown (2009), Murphy (2012) dan situs StreetLiveTalk.com, kedua siklus ekonomi dan siklus bursa digambarkan mirip dengan kurva sinus dan cosinus, seperti yang diilustrasikan oleh Larson, Hostetler, dan Edwards (2008). Mengacu pada kurva Larson, Hostetler, dan Edwards (2008), dihubungkan dengan kedua siklus, maka kurva Sin(x) mewakili siklus bursa serta kurva $\operatorname{Cos}(\mathrm{x})$ mewakili siklus ekonomi. Semua referensi tentang hubungan sektor industri, siklus bisnis dan siklus bursa memiliki pola yang sama dan ada juga yang unik untuk dianalisis, yaitu seperti berikut.

Pertama, rentang antara satu sektor bisnis dengan sektor bisnis lainnya adalah sama, hipotesis peneliti berpendapat bahwa seharusnya rentang antara satu sektor bisnis dengan sektor bisnis lainnya tidaklah sama. Dalam teori manajemen keuangan dan manajemen portofolio, setiap industri akan memiliki risiko sistematis dan risiko nonsistematis. Risiko sistematis tidak dapat dihindari oleh investor yang mengalokasikan investasinya pada satu atau beberapa sektor yang dikenal dengan risiko beta. Sedangkan risiko nonsistematis dapat dihindari investor karena bersifat unik pada setiap industri ataupun emiten. Walaupun risiko beta tidak dapat dihindari oleh semua sektor industri atau sektor bisnis, reaksi akibat faktor ekonomi makro terhadap ekonomi mikro setiap industri berbeda-risiko beta setiap industri berbeda. Oleh karenanya jarak antarsektor industri seharusnya berbeda.

Kedua, mengacu pada kurva $\operatorname{Sin}(\mathrm{x})$ dan $\operatorname{Cos}(\mathrm{x})$, maka keduanya memiliki hubungan matematis: $\operatorname{Cos}(\mathrm{x})=\operatorname{Sin}(\mathrm{x}+90)$; alias nilai kurva $\operatorname{Cos}(\mathrm{x})$ akan "lebih cepat" 90 derajat daripada nilai kurva Sin(x). Artinya, bahwa bursa pergerakan titik dalam siklus bursa lebih cepat 90 derajat daripada pergerakan titik siklus ekonomi. Penjelasan yang meliputi teori ekonomi dan manajemen keuangan adalah: periode pemutakhiran (updating) data yang terjadi di bursa saham dapat dilakukan setiap hari (bahkan per detik dengan realtime data yang terhubung dengan server anggota bursa saham); sedangkan pemutakhiran data ekonomi dengan publikasi resmi paling cepat adalah 12 bulan sesudahnya. Walaupun demikian, pelaku bursa masih dapat mencari berita ekonomi makro dan mikro dari berita sehari-hari baik yang dipublikasikan dalam media elektronik ataupun media tulis, hanya saja kontinuitas kesamaan berita setiap hari tentu tidak selalu sama atau tergantung headlight topics yang sedang ramai dibicarakan oleh publik. Sehingga akan terjadi kekosongan data kuantitatif ataupun kualitatif. Pengembangan simulasi pada intinya adalah sebuah model matematis yang dibuat berdasarkan data statistik untuk meramalkan kejadian pada waktu berikutnya. Siklus ekonomi sulit diramalkan dengan pemutakhiran data berperiode pendek sekalipun, karena memiliki prediktor yang lemah dengan data realtime (Diebold \& Rudebusch, 1999). 


\section{Tampilan Simulasi}

Tampilan simulasi dapat dilihat pada beberapa sheet. Tampilan utama dapat dilihat pada sheet bernama JKSE yang terdiri dari grafik JKSE dan siklus sektor industri (business cycle). Pada grafik JKSE garis biru yang mewakili indeks JKSE aktual sampai dengan titik terakhir (red point) dan garis coklat sebagai garis prediksi (Prediction) sampai 5 hari ke sesudah red point seperti berikut.

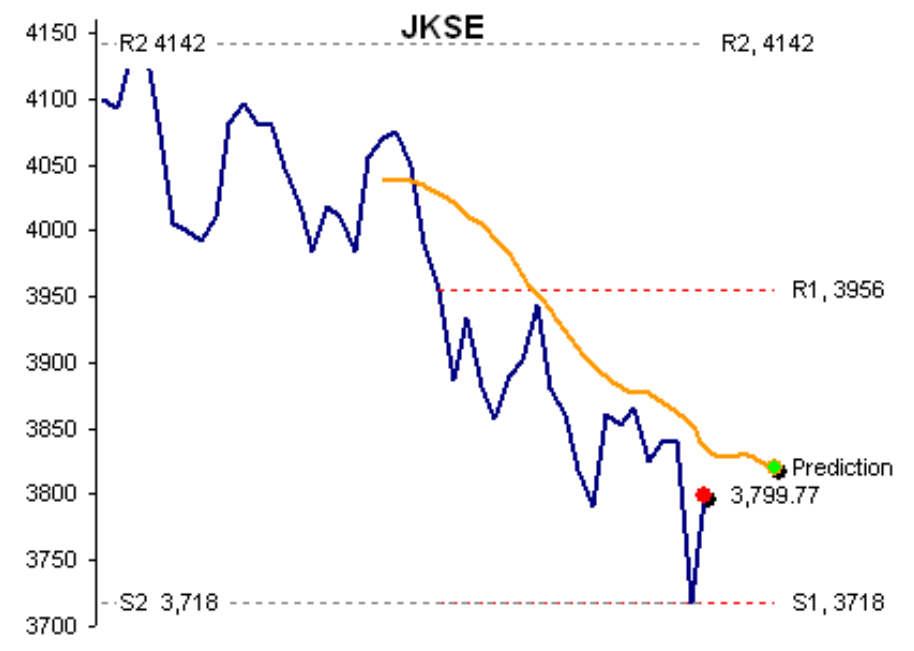

Gambar 1 Tampilan Simulasi Grafik JKSE

Garis prediksi tetap menggunakan data-data sebelum redpoint (tidak menggunakan data sesudahnya), agar konsisten dan fair bahwa simulasi yang terjadi tidak mengetahui masa depan-dan memang tidak ada seorang pun yang akan mengetahui masa depan. Sehingga prediksi menggunakan fungsi statistik peramalan dengan metode WSMA (Weighted Smoothing Moving Average). Titik hijau (green point) pada akhir selanjutnya dianalisis lebih dalam dan dihubungkan dengan siklus sektor industri agar player dapat melakukan business rotation.Tampilannya merupakan gabungan antara teori atau konsep utama analisis teknikal dari beberapa sumber dan www.streettalklive.com. Posisi terakhir kondisi bursa akan diwakili oleh titik merah pada siklus sektor industri-yang disesuaikan secara otomatis dan simultan terhadap pergerakan garis prediksi. Contoh tersesebut menunjukkan bahwa saat ini kondisi bursa masih cenderung turun atau downtrend, sehingga sektor industri yang direkomendasikan adalah sector-sektor yang bersifat "tahan banting" terhadap kondisi bursa serta dapat meminimalisir tingkat inflasi misal: Healthcare, Utilities, dan Finance. Rekomendasi tersebut jika dikonversikan ke dalam 10 sektor industri versi BEI menjadi sektor industri Finance, Consumer Goods, Basic Industries dan Infrastuctures \& Utilities.

Siklus ekonomi sayang sekali tidak bisa ditampilkan, karena memang data-data pendukung siklus tersebut "sangat lambat" di-update oleh badan-badan resmi terkait dengan ekonomi, industri dan pasar modal. Bahkan data tersebut justru lebih cepat dipublikasikan oleh badan dunia semacam World Bank, walaupun terlambat 1- 3 bulan. Kendala lainnya, walaupun data-data sudah didapat, data-data tersebut tidak bisa serta-merta dilibatkan dalam pergerakan simulasi yang simultan tadi, karena perbedaan interval update data yang terlalu jauh, yaitu: data siklus ekonomi dalam interval tahunan sementara data siklus bursa dalam interval harian. Simulasi ini terbatas pada data historis tahun 2000 sampai dengan November 2012, player akan sulit hafal dengan pergerakan bursa, karena selain terdapat lebih dari 3.067 data harian yang dapat diurai menjadi 10 sektor industri, berarti terdapat lebih 
dari 30.670 titik (data) yang bergerak simultan, serta awal periode simulasi dilakukan secara acak oleh komputer dengan waktu simulasi 5 - 20 menit, tergantung player setting sebelum memulai simulasi, dengan perpindahan hari 20 detik. Pengembangan simulasi dilakukan dalam dua jenis: Entry \& Exit Simulation dan Business Rotation Simulation. Exit \& Entry Simulation ditujukan untuk melatih player dalam menganalisis siklus bursa, sedangkan Business Rotation Simulation memiliki tingkat kesulitan yang lebih tinggi, bertujuan selain player menganalisis bursa, pada saat yang sama player juga harus melakukan business rotation dan optimalisasi portofolionya dengan linear programming.

\section{Entry and Exit Market Simulation}

Berikut contoh simulasi selama 263 hari dengan modal awal Rp10 juta, semua transaksi akan tercatat dalam Trading List, sebagai berikut.

Tabel 1 Contoh Trading List Hasil Entry and Exit Simulation

$\begin{array}{llrrrr}\text { Simulation Date } & \text { 22-Dec-12 } & \text { Beginning } & 10,000,000 & \text { Trading Day } & 263 \text { days } \\ \text { Player } & \text { Testing } & \text { Ending } & 10,254,505 & \text { RoM } & 2.55 \% \\ \text { Character } & \text { Risk Averter } & \text { Gain (Loss) } & 254,505 & \text { Avg RoM } & 0.01 \% \text { per day }\end{array}$

\begin{tabular}{|c|c|c|c|c|c|c|c|}
\hline$\overline{\text { Day }}$ & Action & Sector & Value & Volume & Total Value & Cash & Total Assets \\
\hline 1 & Beginning & & & & & $10,000,000$ & $10,000,000$ \\
\hline 2 & Buy & $4,055.20$ & $(2,000,000)$ & 493.19 & $2,000,000$ & $8,000,000$ & $10,000,000$ \\
\hline 89 & Buy & $3,984.87$ & $(2,000,000)$ & 995.09 & $3,965,304$ & $6,000,000$ & $9,965,304$ \\
\hline 95 & Sell & $4,114.14$ & $4,093,940$ & - & - & $10,093,940$ & $10,093,940$ \\
\hline 215 & Buy & $3,814.09$ & $(2,000,000)$ & 524.37 & $2,000,000$ & $8,093,940$ & $10,093,940$ \\
\hline 261 & Buy & $3,874.78$ & $(2,000,000)$ & $1,040.53$ & $4,031,831$ & $6,093,940$ & $10,125,770$ \\
\hline 263 & Sell & $3,998.50$ & $4,160,565$ & - & - & $10,254,505$ & $10,254,505$ \\
\hline
\end{tabular}

Tabel simulasi tersebut adalah simulasi analisis Entry and Exit Market berdasarkan indeks bursa (JKSE). Player seolah-olah melakukan transaksi jual-beli terhadap indeks JKSE dengan volume diasumsikan adalah nilai transaksi dibagi dengan nilai JKSE. Transaksi buy dapat dilakukan lebih dari satu kali selama sisa saldo kas mencukupi. Saat player kemudian menekan tombol Sell, maka semua data Volume akan dianggap dijual sekaligus. Contoh dalam tabel, player melakukan dua kali transaksi Buy, sehingga Volume pada transaksi Buy kedua menjadi nilai kumulatif dari volume transaksi pertama dan kedua. Saat player melakukan Sell, maka semua volume akan dijual sekaligus-sehingga kumulatif volume menjadi nol.

\section{Return on Margin}

Nilai aset dalam saham atau indeks akan berubah sesuai dengan fluktuasi yang terjadi dalam simulasi, sehingga dapat bertambah (profit) atau berkurang (rugi) karena fluktuasi bursa, dengan demikian:

$$
R O M=\frac{\text { Beginning }- \text { Ending }}{\text { Beginning }} \times 100 \%
$$

Jika ROM bernilai positif berarti pada pada umumnya hasil simulasi menghasilkan profit; sebaliknya jika bernilai negatif tindakan yang dilakukan player dalam simulasi lebih banyak 
menghasilkan loss. Simulasi ini pun dilengkapi dengan penentuan kriteria player berdasarkan ratarata ROM harian. Periode awal dan akhir simulasi dapat ditentukan secara otomatis, karena komputer mencatat semua tindakan yang dilakukan oleh player dalam Trading_List. Average ROM adalah rata-rata ROM selama periode tersebut, yang dapat mengelompokkan karakter player dengan kriteria berikut:

Tabel 2 Karakter Player Menurut Avg ROM

\begin{tabular}{ll}
\hline Average ROM per day & Player's Characteristics \\
\hline Lebih dari 4\% & Risk Seeker (Speculator) \\
1\% sampai 4\% & Risk Normal (Investor) \\
Kurang dari 1\% & Risk Averter \\
\hline
\end{tabular}

Catatan: Dari berbagai sumber

Tabel tersebut khusus dibandingkan untuk ROM yang menghasilkan positif atau cenderung menghasilkan profit $(\mathrm{ROM}>0)$. Tabel tersebut penting untuk diperhatikan karena menjadi pedoman pemahaman dan produktivitas player saat melakukan simulasi. Sebagai contoh: bandingkan dengan dua hasil simulasi, simulasi pertama menghasilkan ROM 20\% dalam waktu 20 hari sedangkan hasil simulasi kedua menghasilkan ROM 20\% dalam waktu 40 hari. Jika hanya memerhatikan hasil ROM, kedua hasil simulasi diasumsikan memiliki kinerja yang sama, padahal tidak demikian karena kita belum melibatkan faktor waktu. Saat faktor waktu dijadikan waktu penentu kinerja hasil simulasi, maka dengan tegas kita dapat menyatakan bahwa hasil simulasi kedua lebih rendah daripada hasil simulasi pertama, yaitu Avg $\mathrm{ROM}_{1}=1 \%$ per day sedangkan AVG $\mathrm{ROM}_{2}=0,5 \%$ per day. Lebih lanjut, walaupun hasil simulasi pertama memiliki ROM positif, tetapi kinerja tersebut masih tergolong Risk Averter (penghindar risiko).

\section{Sector Rotation Simulation}

Pada intinya simulasi ini mirip dengan sebelumnya. Perbedaan utama terletak pada variasi “asset” tidak hanya JKSE seperti simulasi jenis pertama, melainkan terdapat pilihan 10 sektor industri yang bergerak simultan. Contoh berikut menggambarkan hasil simulasi memiliki ROM negatif dengan rata-rata $-0,04 \%$ per hari. Artinya, semua tindakan player menyebabkan total kerugian hampir sebesar Rp780 ribuan dari saldo awal kas sebesar Rp10 juta.

Tabel 3 Contoh Trading List Hasil Business Rotation

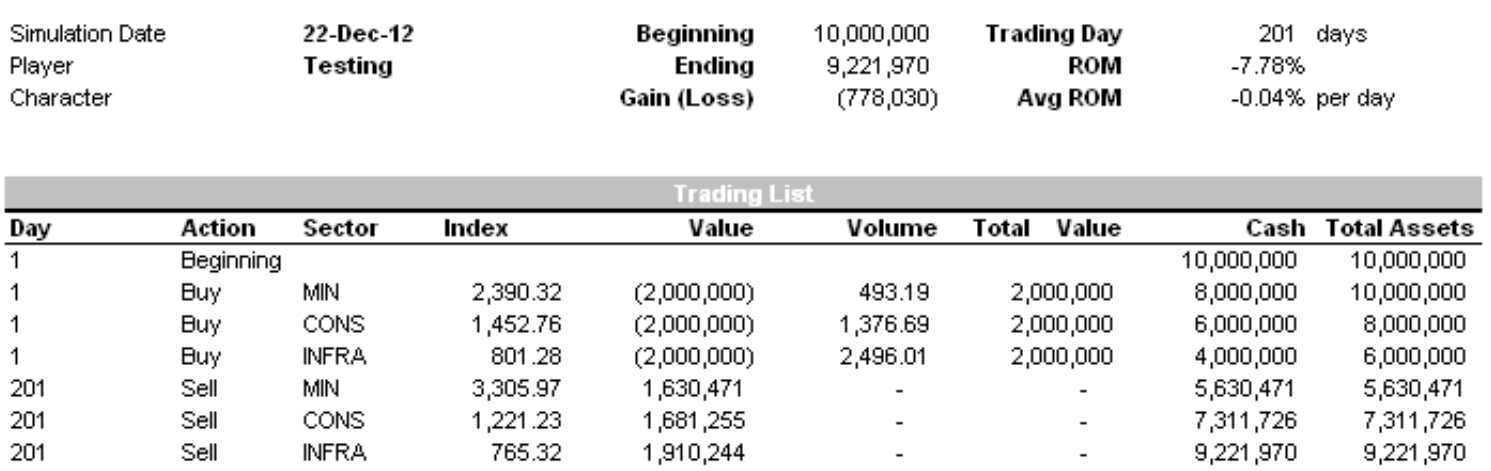




\section{Optimalisasi Portofolio}

Optimalisasi portofolio menggunakan konsep analisis kuantitatif Efficient Frontier dan Markowitz yang didukung dengan Linear Programming karena perlu mencari daerah solusi dengan perhitungan kompleks. Saat ini hanya disediakan maksimum 3 (tiga) combo box untuk memilih kombinasi dari ke-10 sektor industri yang terlibat dalam simulasi. Saat player menekan tombol Optimize, maka komputer akan menjalankan perintah Macro untuk menemukan daerah solusi optimum dari data historis berupa return, total risk, systematic risk, unsystematic risk, correlation between assets, untuk menentukan relevant covarian dan unrelevant covarian, yang pada akhinya komputer melakukan perhitungan berulang (iteration) sampai menemukan kombinasi terbaik (allocation) dalam yang menghasilkan Coefficient of Variation minimum. Berikut contoh tampilan optimalisasi portofolio yang terdiri dari indeks industri dasar (Basic), industri barang - barang konsumen (Consumer) dan industri energi - pertambangan (Mining):

19 May 2000

Portfolio Optimizing with Linear Programming

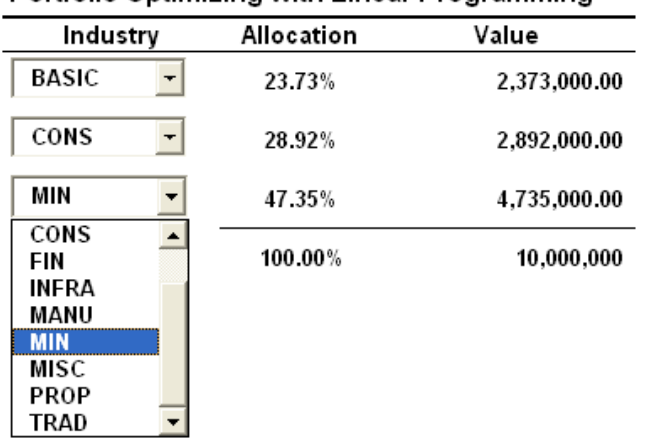

Optimize

Gambar 2 Contoh Optimalisasi Portofolio dengan Linear Programming

\section{SIMPULAN}

Beberapa simpulan yang dapat disampaikan adalah sebagai berikut. Pertama, rancangan model siklus bursa mengadaptasi pola grafik $\operatorname{Sin}(\mathrm{x}) \operatorname{dan} \operatorname{Cos}(\mathrm{x})$ agar menghasilkan kurva yang mulus (smooth). Skenario simulasi dapat dimulai secara otomatis, baik secara random maupun dengan skenario: normal, recession, ataupun booming. Siklus bursa akan melalui pola-pola downtrend, uptrend, ataupun stagnan. Karena keterbatasan data dan perbedaan update interval dari data ekonomi, siklus ekonomi tidak dapat ditampilkan dalam simulasi ini. Kedua, rancangan aplikasi simulasi perdagangan telah dilengkapi dengan garis prediksi 5 hari ke depan dengan menggunakan Weighted Smoothing Moving Average (WSMA). Ujung garis tersebut bergerak simultan dengan siklus sektor industri menjadi pedoman player untuk melakukan business rotation dalam simulasi. Ketiga, rangcangan aplikasi simulasi telah dilengkapi pula dengan optimalisasi portofolio yang merupakan kombinasi model kurva efficient frontier dan linear programming. Tantangan yang harus dilalui seorang player adalah menjaga fokus analisis teknikal bursa, sekaligus membuat keputusan wait, hold, buy, atau sell secara bersamaan selama 5 - 20 menit yang dapat diatur waktunya sebelum memulai simulasi.

Beberapa saran yang dapat disampaikan saat akan melakukan dan setelah melakukan simulasi. Pertama, player yang pertama kali menggunakan simulasi ini diharapkan memilih satu sektor industri sampai simulasi selesai. Hal ini bertujuan agar lebih fokus dan tidak asal tekan tombol BUY atau SELL. Kedua, pada simulasi kedua, player dapat memilih 1 - 2 sektor industri dengan lebih 
memanfaatkan rekomendasi yang diberikan oleh grafik Business Rotation dan menekankan pada monitoring dan evaluasi hasil simulasi berdasarkan sheet bernama Trading_List. Ketiga, pada simulasi ketiga, player dapat memilih 1 - 3 sektor industri, lebih memanfaatkan grafik Business Rotation dan terutama menggunakan optimalisasi portofolionya dengan Linear Programming pada sheet bernama Optimizing. Keempat, pada simulasi selanjutnya, player dapat memulai "kejar target” agar hasil akhir simulasi memiliki Avg ROM lebih besar dari 1\% per hari. Kelima, player tidak perlu bertindak serampangan demi mengejar target. Tujuan akhir pembentukan karakter player adalah Risk Manager bukan Speculator. Artinya, jika memang perlu mengambil risiko yang lebih tinggi karena kondisi pergerakan bursa mendukung demikian-ambil risiko tersebut untuk menghasilkan profit yang lebih tinggi. Saat risiko terlalu tinggi dan kondisi bursa tidak mendukung, lakukan wait and see untuk menghindari kerugian (loss) yang lebih besar. Keenam, statistik hanyalah alat untuk melakukan peramalan, tidak ada satupun metode yang dapat meramalkan 100\% masa depan. Analisis Business Rotation yang dikombinasikan dengan Linear Programming di atas kertas mampu mengefisiensikan portofolio. Saat bursa atau pasar modal bersifat efisien, maka alat ini pun akan lebih akurat digunakan. Gejala market failure karena asymetric information dan incompetitive market turut berperan dalam penentuan harga-harga saham di bursa.

\section{DAFTAR PUSTAKA}

Anderson, D. R., Dennis J. S., Williams, T. A., Camm, J. D., and Martin, K. (2011). An Introduction to Management Science: Quantitative Approaches to Decision Making (13th Edition). South Western Cengage Learning.

Barlow, J. F. (2005). Excel Model for Business and Operations Management (2nd Edition). USA: John Wiley and Sons.

Diebold, F. X., \& Rudbusch, G. D. (1999). Business Cycle: Duration, Dynamics, and Forecasting. Princenton University.

Elton, E. J., \& Gruber, M. J. (2011). Investments and Portfolio Performance. Singapore: World Scientific.

Fabozzi, F. J., \& Choudhry, M. (2004). The Handbook, of European Fixed Income Securities. USA: John Wiley \& Sons.

Fabozzi, F. J. (2007). Fixed Income Analysis (2nd Edition). CFA Institute.

Guerrero, H. (2010). Excel Data Analysis: Modeling and Simulation. Springer.

Kettell, B. (2002). Economics for Financial Markets. Butterworth - Heinemann Finance.

Larson, R., Hostetler, R., \& Edwards, B. H. (2008). Precalculus Functions and Graphs: A Graphing Approach ( $5^{\text {th }}$ Edition). Cengage Learning.

Murphy, J. J. (2011). Intermarket Analysis: Plotting From Global Market Relationships. Wiley.

Owen, D., \& Griffith, R. (2006). Mapping The Markets: Guide to Stockmarkets Analysis. Bloomberg.

Reilly, F. K., \& Brown, K. C. (2009). Investment Analysis and Portofolio Management, (7 $7^{\text {th }}$ Edition). South-Western - Thomson Learning. 